OPEN ACCESS

Edited by:

Yiqiang Zhan,

Karolinska Institutet (KI), Sweden

Reviewed by:

Livio Provenzi,

Eugenio Medea (IRCCS), Italy

Jonas Ranstam,

Mdas AB, Sweden

*Correspondence:

Jinshan Wang

jinshan.wangdr@hotmail.com

Specialty section:

This article was submitted to Endocrinology of Aging,

a section of the journal

Frontiers in Endocrinology

Received: 04 August 2017 Accepted: 01 September 2017 Published: 14 September 2017

Citation:

Yang $M$, Jiang $P$, Jin $C$ and Wang $J$

(2017) Longer Telomere Length and its Association with

Lower Levels of C-Peptide.

Front. Endocrinol. 8:244.

doi: 10.3389/fendo.2017.00244

\section{Longer Telomere Length and its Association with Lower Levels of C-Peptide}

\author{
Min Yang ${ }^{1}$, Ping Jiang ${ }^{1}$, Chenghao Jin ${ }^{1}$ and Jinshan Wang ${ }^{2 *}$ \\ ${ }^{1}$ Department of Respiration, Tianjin First Center Hospital, Tianjin, China, ${ }^{2}$ Department of Transplantation, Tianjin First Center \\ Hospital, Tianjin, China
}

Background: Telomeres undergo shortening with each cell division, which could be accelerated by increase obesity and is also related to endocrinology systems. In this study, we aimed to examine the complex association between telomere, C-peptide, and obesity as well as chronic inflammation in a large population-based cross-sectional survey.

Methods: We used data from a community-based population study, where around 1,382 participants were recruited and had telomere length measured. The association of telomere length with $\mathrm{C}$-peptide was studied using multiple linear regression models. We also examined if obesity, measured by body mass index (BMI), and inflammation could affect this observed association.

Results: Around $48 \%$ of these participants were men and 52\% were women. The average ages were 51.7 years old for men and 49.1 years old for women. After controlling for age and sex, $1 \mathrm{U}$ increase of telomere length was associated with $-0.17(-0.28,-0.06)$ unit decrease of $\mathrm{C}$-peptide. Additionally controlling for BMI, the association magnitude was decreased to $-0.13(-0.23,-0.04)$. Further adjusting for inflammation biomarker did not change the effect estimates.

Conclusion: Longer telomere was associated with lower levels of C-peptide. This association could be attenuated by adjusting for obesity.

Keywords: telomere, C-peptide, obesity, endocrinology, National Health and Nutrition Examination Survey

\section{INTRODUCTION}

Telomeres are repeated deoxyribonucleic acid sequences and surrounding proteins at the end of chromosomes. The length of telomere (TL) shortens gradually overtime during each cell division and recognized as a promising biomarker of aging (1). TL declines with increasing age in human beings and has been associated with type 2 diabetes $(2,3)$, cardiovascular disease $(4,5)$, obesity $(6)$, insulin resistance $(4,7)$, and other chronic conditions $(5,8,9)$. However, its association with C-peptide has rarely been investigated (10-12). A case-control study found TL to be associated with C-peptide (10), similar results were observed in a cross-sectional study (13). However, other studies did not find a correlation between TL and C-peptide $(11,12)$. C-peptide is a short polypeptide with 31-aminoacid and relates insulin's A-chain to its B-chain in the proinsulin molecule. In diabetes and other diseases, peripheral blood C-peptide assessment can be used to distinguish between certain diseases with similar clinical features, such as type 1 and type 2 diabetes. Examining the relationship of TL 
with C-peptide could provide additional information regarding the role of telomere in metabolic diseases regulation given the high prevalence of diabetes $(14,15)$. Because obesity was associated with both TL (6) and C-peptide (16), the association of TL and C-peptide could be confounded by obesity. In this study, we hypothesized that longer TL could be associated with lower levels of C-peptide, which could be attenuated by obesity. This hypothesis is to be evaluated by using the large community-based data in The National Health and Nutrition Examination Survey (NHANES).

\section{MATERIALS AND METHODS}

\section{Study Population}

The NHANES survey is a continuous study that is being performed by the Centers for Disease Control and Prevention (CDC) that provides estimates of the health, chronic disease, and nutrition status of U.S. residents. In this study, we use data from the 1999 to 2000 cycles, where participants were given options to provide blood samples and had their telomere measured. The data collection of the NHANES has been approved by the National Center for Health Statistics Ethics Review Board. Written informed consent was acquired from each NHANES participant.

\section{Telomere Length Assessment}

The details of telomere length assessment were described elsewhere (17). Processed DNA was provided by the laboratory of the NHANES Division in the CDC, U.S. Peripheral blood samples were used to extract the DNA, which were then stored at $-80^{\circ} \mathrm{C}$. The assessment of the TL was conducted in the laboratory in UCSF using the standard quantitative polymerase chain reaction method to estimate the relative telomere length by comparing it to the standard reference length of DNA (reported as T/S ratio). All samples were tested triple in three different days. We calculated the mean of the $\mathrm{T} / \mathrm{S}$ ratio values and marked the measured values which were greater than 0.4 compared with the mean $\mathrm{T} / \mathrm{S}$ ratio as an outlier. In total, around $1.3 \%$ of all samples contained outliers.

\section{C-Peptide Measurements}

$\mathrm{C}$-peptide was measured using the radioimmunoassay that is a competitive assay. A fixed and known amount of iodine 125-labeled C-peptide was added and incubated in this assay. During this incubation period, the radiolabeled C-peptide could bind to available sites. Then, the unbounded and bounded antibodies are separated by precipitation. The C-peptide levels are then estimated by plotting a calibration curve.

\section{Statistical Analysis}

We log-transformed C-peptide to make it normally distributed. The distributions of C-peptide and log-transformed C-peptide were presented in Figure 1. We used multiple linear regression models to assess and test the association between C-peptide and TL. Continuous variables were presented by mean and SDs and category variables were described as number and proportions. Four models were used to estimate the association. The first model was the crude analysis where the dependent variable is the
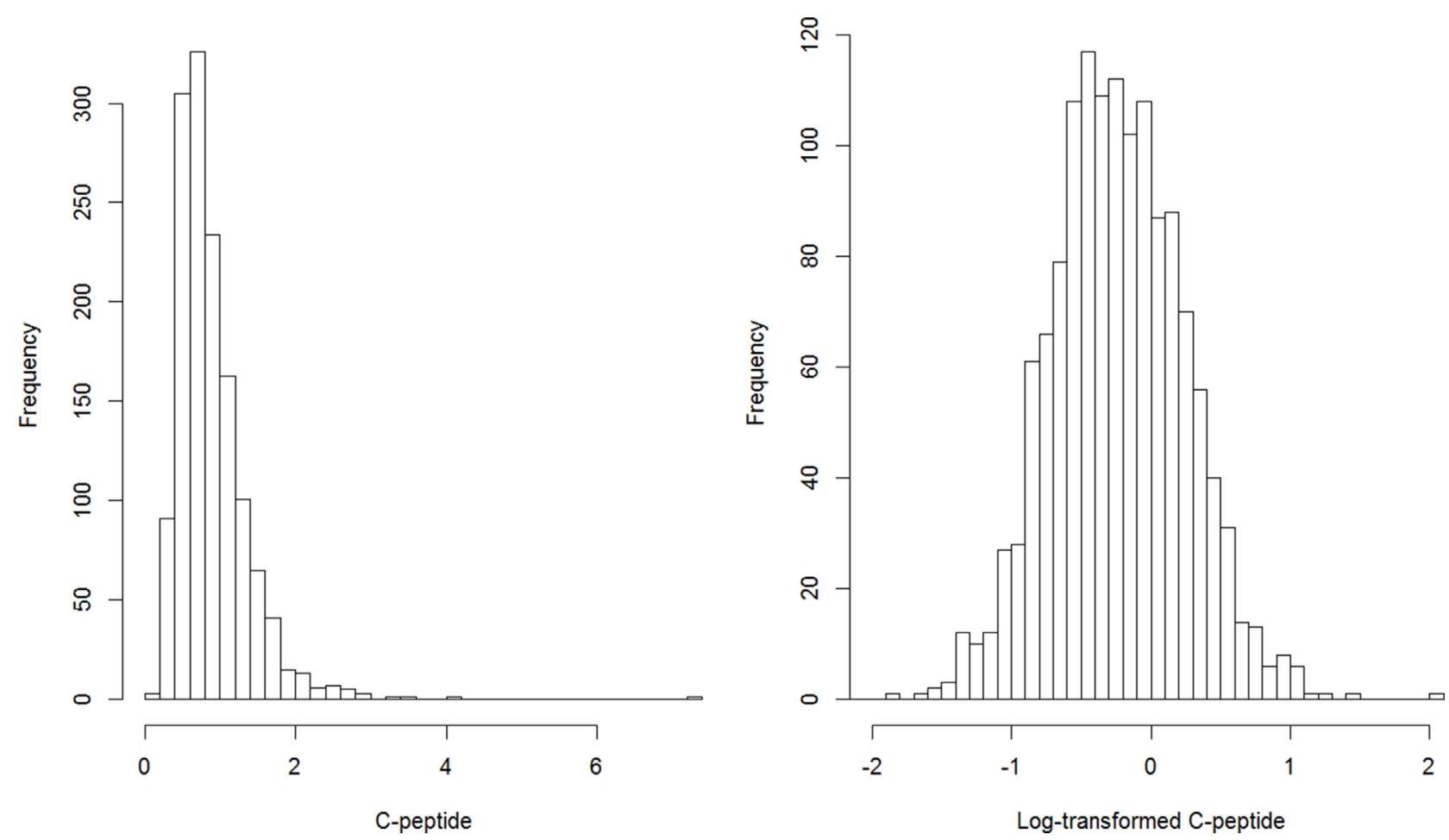

FIGURE 1 | Distribution of C-peptide and Log-transformed C-peptide. 
log-transformed C-peptide and independent variable is telomere length. The second model was adjusted by age and sex. The third model was further adjusted for body mass index (BMI). The fourth model was additionally controlled by $\mathrm{C}$-reactive protein (CRP). We also presented the scatter plot of telomere length and C-peptide by obesity (Figure 2). Sampling survey design was taken into account of in the multiple regression models using the survey package in $\mathrm{R}$. Two sided $P$-value $<0.05$ was considered as statistically significant. All analyses were conducted using R 3.3.

\section{RESULTS}

Basic characteristics of study participants are presented by sex in Table 1. In total, 1,382 participants had both telomere and C-peptide data available, of which 665 (48.1\%) were men and 717 (51.9\%) were women. The average ages were 51.7 years old for men and 49.1 years old for women. Women had slightly longer TL compared with men (0.98 vs. $0.97 \mathrm{~T} / \mathrm{S}$ ratio), but lower logtransformed C-peptide ( -0.27 vs. $-0.21 \mathrm{nmol} / \mathrm{L})$.

Figure 1 describes the distribution of original C-peptide and log-transformed C-peptide. After log-transformation,

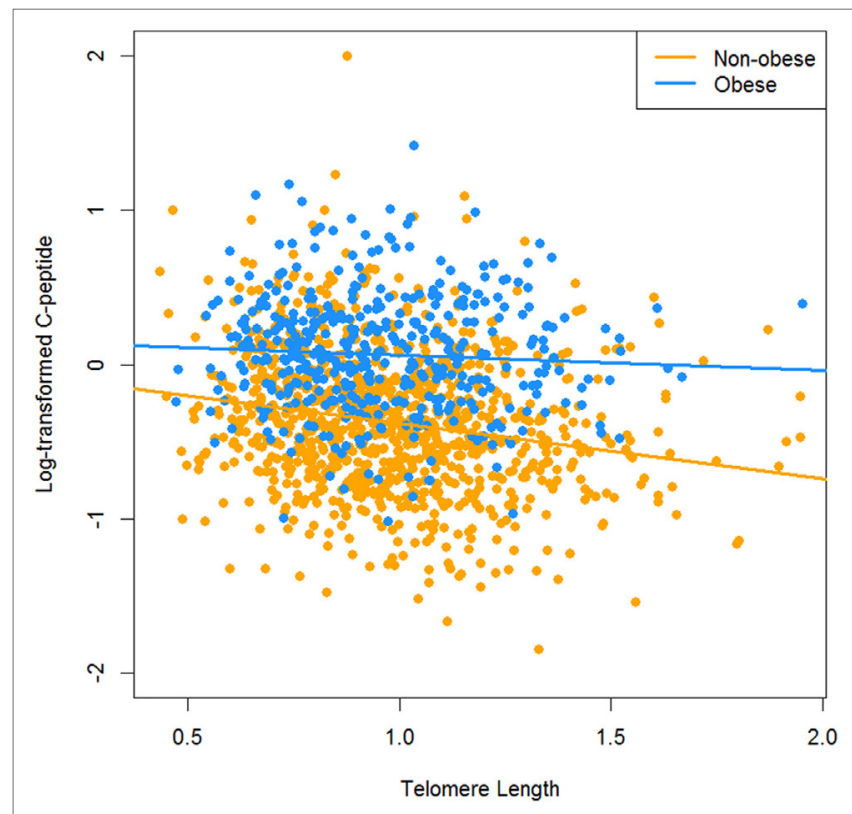

FIGURE 2 | The relationship between C-peptide and telomere length by obesity.

TABLE 1 | Basic characteristics of study participants.

\begin{tabular}{lccc}
\hline Variables & Men $(\boldsymbol{n}=\mathbf{6 6 5})$ & Women $(\boldsymbol{n}=\mathbf{7 1 7})$ & All $(\boldsymbol{n}=\mathbf{1 , 3 8 2})$ \\
\hline Age (years) & $51.7(18.6)$ & $49.0(19.0)$ & $50.3(18.8)$ \\
Telomere length (T/S ratio) & $0.97(0.26)$ & $0.98(0.23)$ & $0.97(0.25)$ \\
Log-transformed & $-0.21(0.48)$ & $-0.27(0.49)$ & $-0.24(0.49)$ \\
C-peptide (nmol/L) & & & \\
C-reactive protein (mg/dL) & $0.39(0.82)$ & $0.55(0.72)$ & $0.47(0.77)$ \\
Height (cm) & $173.4(7.8)$ & $160.0(7.5)$ & $166.6(10.1)$ \\
Weight (kg) & $84.0(17.6)$ & $72.1(16.9)$ & $77.8(18.2)$ \\
Body mass index $\left(\mathrm{kg} / \mathrm{m}^{2}\right)$ & $27.8(5.0)$ & $28.0(6.1)$ & $28.0(5.6)$
\end{tabular}

the distribution of C-peptide approaches normal distribution. Table 2 describes the association of TL with C-peptide in this population. We first categorized TL to thirds and used categorical $\mathrm{TL}$ as the independent variable to estimate its association with log-transformed C-peptide. Compared with the lowest thirds, people in the highest thirds of TL had -0.20 (95\% CI: -0.26 , $-0.14) \mathrm{nmol} / \mathrm{L}$ lower C-peptide in the first model. The effect size was attenuated after adjusting for age and sex in the second model ( $\beta$ : marginal effect $=-0.11,95 \% \mathrm{CI}:-0.18,-0.05)$. After further controlling for BMI, the magnitude was decreased to -0.09 (95\% CI: $-0.14,-0.03)$. In addition, adjustment of CRP did not change the association. We also modeled TL as a continuous variable, $1 \mathrm{U}$ increase of TL was association with -0.13 (95\% CI: $-0.22,-0.04)$ decreased of log-transformed C-peptide when controlling for age, sex, BMI, and CRP in the fourth model. Analysis by obesity status was presented in Table 3; however, the interaction term between obesity and TL was not statistically significant.

\section{DISCUSSION}

In this study, we hypothesized TL to be associated with C-peptide and this association could be attenuated by obesity. We examined the association in a large population-based survey using the NHANES data and found that longer TL was association with lower levels of C-peptide. This observed association remained statistically significant after controlling for multiple covariates, but was attenuated with obesity adjustment. In addition, taking into account of CRP in the models did not change the association magnitude, suggesting that TL might influence C-peptide through biological pathways beyond inflammation.

Length of telomere has been shown to be predictive of diabetes and related glycemic traits in both observational population studies $(2,3,7)$ and animal experiments $(18,19)$. However, its association with C-peptide has seldom been examined. A casecontrol study with 15 participants did not find a significant correlation between TL and C-peptide (11). Another study in 52 new infants of mothers with gestational diabetes and pre-gestational diabetes assessed both TL and C-peptide in this sample, but did not extensively examined their association (12). However, in a large study with 556 newly diagnosed diabetic patients, TL was negatively correlated with C-peptide although the association did not reach a significance level (13). Similar findings were observed in a case-control study of pancreatic cancer, in which TL was statistically significantly correlated with C-peptide in both cases and controls (10). Our results were in line with these findings, but with large sample size and more detailed investigation.

Previous studies have shown obesity and inflammation were associated with TL $(6,20-22)$. Obese people had shorter TL compared with their lean peers (6) and oxidative stress and inflammation could accelerate TL shortening (22-24). Likewise, obesity and inflammation are two important risk factors for glycemic traits including diabetes, insulin resistance, and C-peptide $(16,25,26)$. It is thus nature to hypothesize obesity and inflammation could be the common causes of both TL and C-peptide. In this study, we tested these relationship hypothesis and the results did not contradict it. When controlling for BMI, the association magnitude was attenuated by approximately $30 \%$. This means 
TABLE 2 | Association between telomere length and C-peptide, $\beta$ (95\% Cl).

\begin{tabular}{lccc}
\hline Telomere length & Model 1 & Model 2 & Model 3 \\
\hline Thirds 1 $(0.43-)$ & Reference & Reference & Reference \\
Thirds 2 $(0.84-)$ & $-0.09(-0.16,-0.03)$ & $-0.05(-0.11,0.01)$ & $-0.03(-0.08,0.02)$ \\
Thirds 3 (1.06-) & $-0.20(-0.26,-0.14)$ & $-0.11(-0.18,-0.05)$ & $-0.09(-0.14,-0.03)$ \\
Continuous & $-0.33(-0.43,-0.23)$ & $-0.18(-0.29,-0.07)$ & $-0.13(-0.23,-0.04)$ \\
\hline
\end{tabular}

Results from Model 1 were the crude estimates. Model 2 was adjusted for age and sex, while Model 3 was further adjusted for body mass index, followed by Model 4 with

C-reactive protein adjustment.

TABLE 3 | Association between telomere length and C-peptide by obesity, $\beta(95 \% \mathrm{Cl})$.

\begin{tabular}{lcc}
\hline Telomere length & Obese & Non-obese \\
\hline Quarters 1 (0.43-) & Reference & Reference \\
Quarters 2 (0.79-) & $-0.001(-0.10,0.10)$ & $-0.02(-0.10,0.06)$ \\
Quarters 3 (0.95-) & $0.001(-0.10,0.11)$ & $-0.12(-0.21,-0.04)$ \\
Quarters 4 (1.13-) & $-0.009(-0.10,0.12)$ & $-0.12(-0.20,-0.03)$ \\
Continuous & $-0.001(-0.16,0.16)$ & $-0.19(-0.31,-0.07)$ \\
\hline
\end{tabular}

Model was adjusted for age, sex, and C-reactive protein.

obesity could be able to accelerate TL shortening and to drive C-peptide levels up. However, when additionally controlling for CRP, the magnitude did not change any more. As both the obesity and inflammation were involved in metabolic disorder pathogenesis, additionally controlling for one of them when the other was already adjusted for would not affect the models too much.

There were several strengths associated with this study. First, telomere length was measured by a lab using well-established methods. Second, the study participants were randomly selected by NHANES. The sample size was large and representative of the wide age span, allowing the generalization of these results. Finally, we made adjustments in the statistical models for a number of covariates, including age, sex, BMI, and CRP. Findings indicated that the relationship between telomere length and C-peptide was independent of these factors. However, limitations should also be acknowledged. The nature of cross-sectional study makes it difficult to draw causal inference based on our analyses. Both BMI and CRP could also be affected by TL, and additional adjustment of BMI and CRP could underestimate the total effect of TL on C-peptide. However, in this study, all these biomarkers were measured at the same time, and it is difficult to distinguish the cause and consequence among them. Thus, both the unadjusted and adjusted estimates were provided. Although multiple regression models were used, there are still many other variables that might confound the observed

\section{REFERENCES}

1. Blackburn EH, Epel ES, Lin J. Human telomere biology: a contributory and interactive factor in aging, disease risks, and protection. Science (2015) 350(6265):1193-8. doi:10.1126/science.aab3389

2. Zhao J, Zhu Y, Lin J, Matsuguchi T, Blackburn E, Zhang Y, et al. Short leukocyte telomere length predicts risk of diabetes in American Indians: the strong heart family study. Diabetes (2014) 63(1):354-62. doi:10.2337/ db13-0744

3. Zee RY, Castonguay AJ, Barton NS, Germer S, Martin M. Mean leukocyte telomere length shortening and type 2 diabetes mellitus: a case-control study. Transl Res (2010) 155(4):166-9. doi:10.1016/j.trsl.2009.09.012 association. Residual confounding should be taken into account of in future analyses. Besides that, this study did not include genetic variants or telomerase activity assessment. Examining these two biomarkers could definitely provide more evidence to justify our results. Additional limitations include the use of $P$-value as statistical significance criteria. We should acknowledge that the statistically significant finding in our study may not imply clinical significance in practice and the lack of statistical significant evidence does not mean the evidence of absence, e.g., the interaction between obesity and telomere. Thus, our findings should be interpreted with caution.

In summary, this study shows that longer TL was associated with C-peptide in the participants of NHANES, suggesting that TL may be regarded as a predictive biomarker of glycemic traits. Although our findings are derived in a cross-sectional survey, the finding of TL as a prognostic biological aging biomarker for C-peptide, independent of obesity and CRP, may increase our knowledge to assess disease risk and may also increase our understanding of the underlying pathways and mechanisms for the association of biological aging with a wide range of metabolic disorders.

\section{ETHICS STATEMENT}

This study was carried out in accordance with the recommendations of National Center for Health Statistics Ethics Review Board with written informed consent from all subjects. All subjects gave written informed consent in accordance with the Declaration of Helsinki. The protocol was approved by the National Center for Health Statistics Ethics Review Board.

\section{AUTHOR CONTRIBUTIONS}

JW and MY designed and analyzed the data. MY, PJ, and CJ wrote the manuscript. All the authors critically revised and approved the manuscript.

4. Zhan Y, Karlsson IK, Karlsson R, Tillander A, Reynolds CA, Pedersen NL, et al. Exploring the causal pathway from telomere length to coronary heart disease: a network Mendelian randomization study. Circ Res (2017) 121(3):214-9. doi:10.1161/CIRCRESAHA.116.310517

5. Telomeres Mendelian Randomization Collaboration, Haycock PC, Burgess S, Nounu A, Zheng J, Okoli GN, et al. Association between telomere length and risk of cancer and non-neoplastic diseases: a Mendelian randomization study. JAMA Oncol (2017) 3(5):636-51. doi:10.1001/jamaoncol.2016.5945

6. Mundstock E, Sarria EE, Zatti H, Mattos Louzada F, Kich Grun L, Herbert Jones M, et al. Effect of obesity on telomere length: systematic review and meta-analysis. Obesity (Silver Spring) (2015) 23(11):2165-74. doi:10.1002/ oby. 21183 
7. Verhulst S, Dalgård C, Labat C, Kark JD, Kimura M, Christensen K, et al. A short leucocyte telomere length is associated with development of insulin resistance.Diabetologia (2016) 59(6):1258-65. doi:10.1007/s00125-016-3915-6

8. Hägg S, Zhan Y, Karlsson R, Gerritsen L, Ploner A, van der Lee SJ, et al. Short telomere length is associated with impaired cognitive performance in European ancestry cohorts. Transl Psychiatry (2017) 7(4):e1100. doi:10.1038/tp.2017.73

9. Zhan Y, Song C, Karlsson R, Tillander A, Reynolds CA, Pedersen NL, et al. Telomere length shortening and Alzheimer disease - a Mendelian randomization study. JAMA Neurol (2015) 72(10):1202-3. doi:10.1001/jamaneurol.2015.1513

10. Campa D, Mergarten B, De Vivo I, Boutron-Ruault MC, Racine A, Severi G, et al. Leukocyte telomere length in relation to pancreatic cancer risk: a prospective study. Cancer Epidemiol Biomarkers Prev (2014) 23(11):2447-54. doi:10.1158/1055-9965.EPI-14-0247

11. Zhou MC, Min R, Ji JJ, Zhang S, Tong AL, Xu JP, et al. Analysis of association among clinical features and shorter leukocyte telomere length in mitochondrial diabetes with m.3243A $>$ G mitochondrial DNA mutation. BMC Med Genet (2015) 16:92. doi:10.1186/s12881-015-0238-2

12. Gilfillan C, Naidu P, Gunawan F, Hassan F, Tian P, Elwood N. Leukocyte telomere length in the neonatal offspring of mothers with gestational and pre-gestational diabetes. PLoS One (2016) 11(10):e0163824. doi:10.1371/ journal.pone.0163824

13. Zhou M, Zhu L, Cui X, Feng L, Zhao X, He S, et al. Influence of diet on leukocyte telomere length, markers of inflammation and oxidative stress in individuals with varied glucose tolerance: a Chinese population study. Nutr J (2016) 15:39. doi:10.1186/s12937-016-0157-x

14. Menke A, Casagrande S, Geiss L, Cowie CC. Prevalence of and trends in diabetes among adults in the United States, 1988-2012. JAMA (2015) 314(10):1021-9. doi:10.1001/jama.2015.10029

15. Zhan Y, Tang Z, Yu J. Serum ferritin, diabetes, diabetes control, and insulin resistance. Acta Diabetol (2014) 51(6):991-8. doi:10.1007/s00592-014-0656-1

16. Irwin ML, McTiernan A, Bernstein L, Gilliland FD, Baumgartner R, Baumgartner $\mathrm{K}$, et al. Relationship of obesity and physical activity with C-peptide, leptin, and insulin-like growth factors in breast cancer survivors. Cancer Epidemiol Biomarkers Prev (2005) 14(12):2881-8. doi:10.1158/10559965.EPI-05-0185

17. Needham BL, Rehkopf D, Adler N, Gregorich S, Lin J, Blackburn EH, et al. Leukocyte telomere length and mortality in the National Health and Nutrition Examination Survey, 1999-2002. Epidemiology (2015) 26(4):528-35. doi:10.1097/EDE.0000000000000299
18. Guo N, Parry EM, Li LS, Kembou F, Lauder N, Hussain MA, et al. Short telomeres compromise beta-cell signaling and survival. PLoS One (2011) 6(3):e17858. doi:10.1371/journal.pone.0017858

19. Kuhlow D, Florian S, von Figura G, Weimer S, Schulz N, Petzke KJ, et al. Telomerase deficiency impairs glucose metabolism and insulin secretion. Aging (Albany NY) (2010) 2(10):650-8. doi:10.18632/aging.100200

20. Zannolli R, Mohn A, Buoni S, Pietrobelli A, Messina M, Chiarelli F, et al. Telomere length and obesity. Acta Paediatr (2008) 97(7):952-4. doi:10.1111/j.1651-2227.2008.00783.x

21. Jurk D, Wilson C, Passos JF, Oakley F, Correia-Melo C, Greaves L, et al. Chronic inflammation induces telomere dysfunction and accelerates ageing in mice. Nat Commun (2014) 2:4172. doi:10.1038/ncomms5172

22. Wong JY, De Vivo I, Lin X, Fang SC, Christiani DC. The relationship between inflammatory biomarkers and telomere length in an occupational prospective cohort study. PLoS One (2014) 9(1):e87348. doi:10.1371/journal.pone.0087348

23. Kawanishi S, Oikawa S. Mechanism of telomere shortening by oxidative stress. Ann N Y Acad Sci (2004) 1019:278-84. doi:10.1196/annals.1297.047

24. Coluzzi E, Colamartino M, Cozzi R, Leone S, Meneghini C, O’Callaghan N, et al. Oxidative stress induces persistent telomeric DNA damage responsible for nuclear morphology change in mammalian cells. PLoS One (2014) 9(10):e110963. doi:10.1371/journal.pone.0110963

25. Eckel RH, Kahn SE, Ferrannini E, Goldfine AB, Nathan DM, Schwartz MW, et al. Obesity and type 2 diabetes: what can be unified and what needs to be individualized? J Clin Endocrinol Metab (2011) 96(6):1654-63. doi:10.1210/ jc.2011-0585

26. Westphal SA. Obesity, abdominal obesity, and insulin resistance. Clin Cornerstone (2008) 9(1):23-9; discussion 30-21. doi:10.1016/S1098-3597 (08)60025-3

Conflict of Interest Statement: The authors declare that the research was conducted in the absence of any commercial or financial relationships that could be construed as a potential conflict of interest.

Copyright ( 2017 Yang, Jiang, Jin and Wang. This is an open-access article distributed under the terms of the Creative Commons Attribution License (CC BY). The use, distribution or reproduction in other forums is permitted, provided the original author(s) or licensor are credited and that the original publication in this journal is cited, in accordance with accepted academic practice. No use, distribution or reproduction is permitted which does not comply with these terms. 